\title{
Fatigue failure mechanisms of thin-walled hybrid plate girders
}

\author{
Pavol Juhás ${ }^{1, *}$ \\ ${ }^{1}$ Institute of Technology and Business in České Budějovice, Department of Civil Engineering, \\ Okružní 517/10, 37001 České Budějovice, Czech Republic
}

\begin{abstract}
Steel plate girders of bridges and industrial structures are usually subjected to dynamic fatigue loading. Their thin-slender webs under dynamic fatigue loading are laterally buckling and vibrating. The consequence of that can be arising and successive development of fatigue cracks along the welded connections of the thin webs with flanges and stiffeners. Therefore, the fatigue strength and life/time of thin-walled plate girders depend beside of usual material-technological and structural influences also on stability aspects. Basic knowledge about fatigue failure mechanisms of thin-walled hybrid plate girders is presented with the regard for their local stability, obtained and by theoretical an experimental analyses. The outcome of obtained results is that the fatigue consequences of thin webs vibration can be effectively reduced by appropriate reduction of their slenderness. Therefore, the empirical formula for the limitation of web slenderness has been proposed and recommended for plate girders subjected to dynamic fatigue loading.
\end{abstract}

\section{Introduction}

Generally, it is well known, that behaviour of plate girders depends in large degree on local stability of their flanges and webs. New standards (EN 1993-1-1) classify the cross-sections of plate girders like compact (class 1), quasi compact (classes 2 and 3) or slender (class 4) ones relating to local stability. In the case of compact and quasi compact cross-sections the flanges and webs are stable or relative stable, the stress-strain relations are linear and the simplified calculation procedures can be used. In the case of slender cross-sections, the flanges, webs, or flanges and webs are buckling in dependence on geometrical and material properties and on the level and mode of loading. Therefore, the stress-strain relations are non-linear and the load-carrying of plate girders is decreasing. But the interaction of webs, flanges and stiffeners in individual fields of plate girders has beneficial effect on their loadcarrying capacity load-carrying capacity. Consequently, the actual load-carrying capacity can be generally much higher than theoretical critical capacity - buckling strength. This reflects the post critical behaviour and calculation procedures on the stiffened plate girders with slender cross-sections [1-4].

\footnotetext{
* Corresponding author: 15364@mail.vstecb.cz
} 
Post critical calculation procedures are based on the research of plate girders subjected mainly to static or quasi-static loading. But plate girders are used in many cases for bridges and industrial structures that are subjected to dynamic fatigue loading. This phenomenon reduced the fatigue strength and the life-time of plate girders with slender cross-sections. Therefore, it is very important to know the real load-carrying capacity and behaviour of such plate girders during actual loading process.

The design of plate girders with slender cross-sections, particularly with slender webs is convenient from economical point of view. Hybrid plate girders with slender web and higher strength steel in flanges are especially advantageous in this direction. The paper deals with fatigue failure mechanisms of thin-walled hybrid plate girders from local stability aspects [4-9].

\section{Experimental investigations}

The complete experimental programmes consisted from static and dynamic fatigue tests of 48 plate girders with symmetrical I cross-section of real practical dimensions produced under usual technological conditions. The tested girders were different in geometrical dimensions, stiffened field ratio $\alpha$, web slenderness $\beta$ and combination of flanges and web steels (material and cross-section groups). One half of the tested girders were used for static tests and the other half of similar girders for dynamic fatigue tests [6, 8-9].

The cross-section dimensions in the individual groups were selected to give (at uniform $t_{w}$ thickness and various $b_{w}$ width) slenderness ratio $\beta_{\mathrm{w}}=120,150$ and 180 . The flange dimensions were designed to ensure local stability. Element lengths were linked to $b_{w}$ web width $\left(L \approx 7 b_{w}+800 \mathrm{~mm}\right)$. The intermediate panels had different side ratios $(1 \leq \alpha \leq 3.5)$.

Steels of flanges were: $11523.1,13221.1,15422.5$ and 16224.1 , steel of webs was uniform - 11375.1 (by previous Czech and Slovak material standards).

Scheme of girders and working arrangement of the tests are shown in Fig. 1.

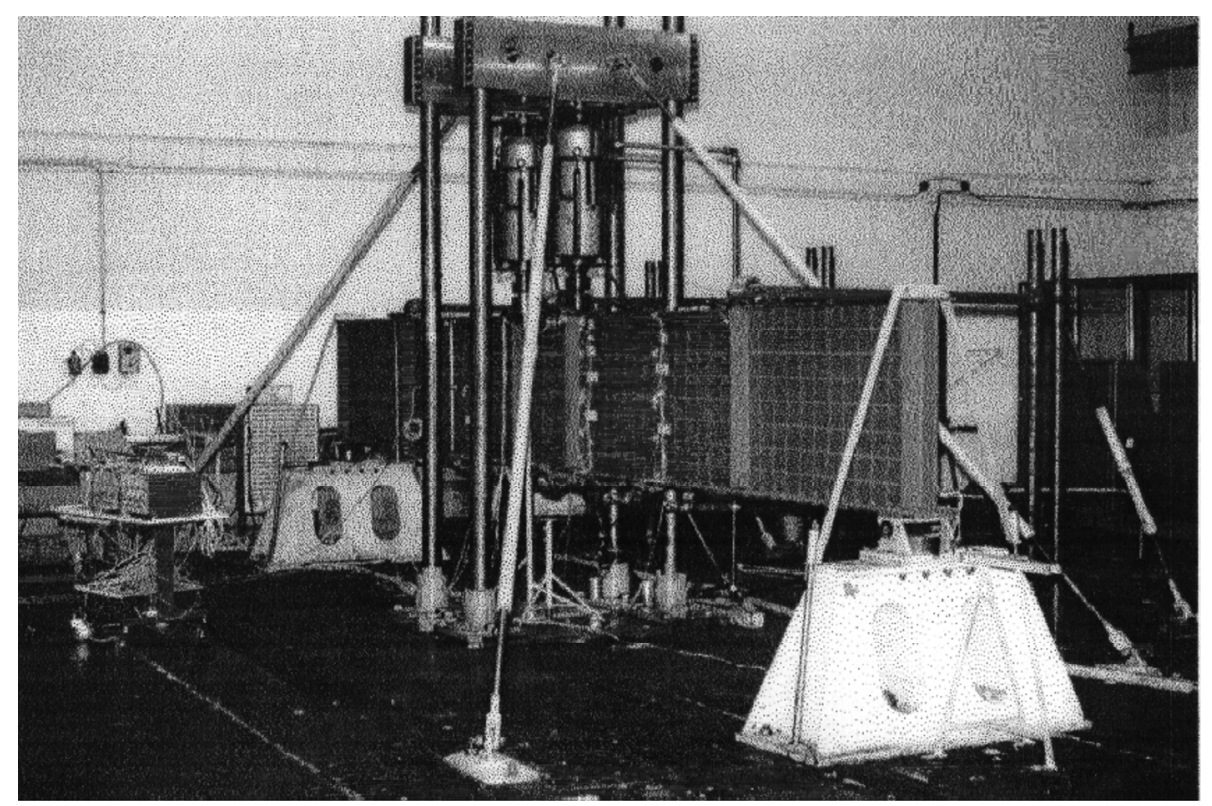

Fig. 1. Scheme of girders and working arrangement of the tests. 
The flanges and webs were machine flame cut. Besides of that the tension flanges of girders were planned. The fillet welds between flanges and webs were made by automatic machine under flux, while stiffeners were hand welded. Prior of testing the true geometrical and material characteristics of the flanges and webs were ascertained. All steels used for the experiments were in conformance with the requirements of applicable standards, or exceeded them. The geometrical and material characteristics, as well as their corresponding deviations from design dimensions and standard material specifications are random variables. Hence, in evaluations of experimental results, either the directly determined or those generally probabilistically - statistically defined values of these variables could be used.

The tested girders were sustained by special vertical and horizontal supports to prevent lateral buckling. The loading was realised by two hydraulic jacks. The tests of girders were divided into two parts. First of all, the girder was loaded by successive loading till to $P_{\max }$ and after that about five cycles between $P=0$ and $P=P_{\max }$ were repeated. Then the fatigue test could start. During fatigue test the girders were loaded by synchronise pulsate loads

$$
\begin{gathered}
P(t)=P_{0}+P_{1} \sin (2 \pi f t), \\
P_{0}=0.5\left(P_{\max }+P_{\min }\right), P_{1}=0.5\left(P_{\max }-P_{\min }\right), \\
P_{\min }=(0.2 \div 0.4) P_{u}, P_{\max }=(0.7 \div 0.8) P_{u},
\end{gathered}
$$

$P_{u}$ is the ultimate static loading including the elastic-plastic post critical behaviour of the web, frequency $f=5.0 \mathrm{~Hz}$.

The behaviour of girders during the static and dynamic tests was ascertained by measurement, registration and evaluation of strains $\varepsilon$ in the most stressed parts (78 strain gauges). The supports sets down $v_{0}$ - deflection pickups 1 and 5, deflection of girder $v_{s}$ in the middle cross-section - deflection pickup 3 and buckling of the web $w$ in the middle points of two stiffened panels - deflection pickups 2 and 4 were also measured. Besides of that we made the detailed measurement of static and dynamic buckling of the web $w$ in different points and cross-sections (I, II, ..., XXII) by movable pickup with graphic evaluation, or by inductive pickup, strain gauge bridge and oscillograph, respectively.

The fatigue tests were realised in stages. After each 50000 cycles the tests were interrupted. Incidental arising of the cracks was ascertained by the detailed observation of the girder with the help of magnifying glass and by direct graphic and tabulate evaluation of strains $\varepsilon$ and deflections $w$ and $v_{s}$ at loads $P=0, P_{\min }, P_{\max }$. The differences between last and previous values of strains $\varepsilon$ in some points of girder indicate arising and placement of fatigue cracks. After arising of the cracks, we followed their development and influence on the global behaviour of girders. The tests continued until the total failure occurred.

\section{Behaviour of tested girders and basic knowledge}

\subsection{Formation of the shapes of the web buckling and vibration}

Under quasi-static loading the thin webs of girders are laterally buckling in dependence on the initial imperfections, geometrical and material parameters and stiffeners of bordered flanges and stiffeners. They are buckling in shapes which correspond to the mechanism of their behaviour according to the process of loading. These shapes are formed already at the beginning of loading process. In accordance with the initial shape a new service shape can be formed by the successive fluent transition or the sudden jump over the web. The service shapes of buckling are decisive for analysis of load-carrying capacity and behaviour of the 
thin webs of plate girders. Under the dynamic fatigue loading the thin webs of girders are laterally vibrating. At the beginning of loading process, the service shape of the web vibration is formed in a similar way to the case of quasi-static loading. During the usual service loading regime in girders the resonant effects do not arise. Therefore, the lateral web deflections which are received at the repeating loading are practically identical with the dynamic lateral web deflections. Under the fixed cyclic loading the levels of deformations, deflections and shape of lateral web vibration did not change at any tested girder till the beginning of fatigue failure. This knowledge is evident from Fig. 2.

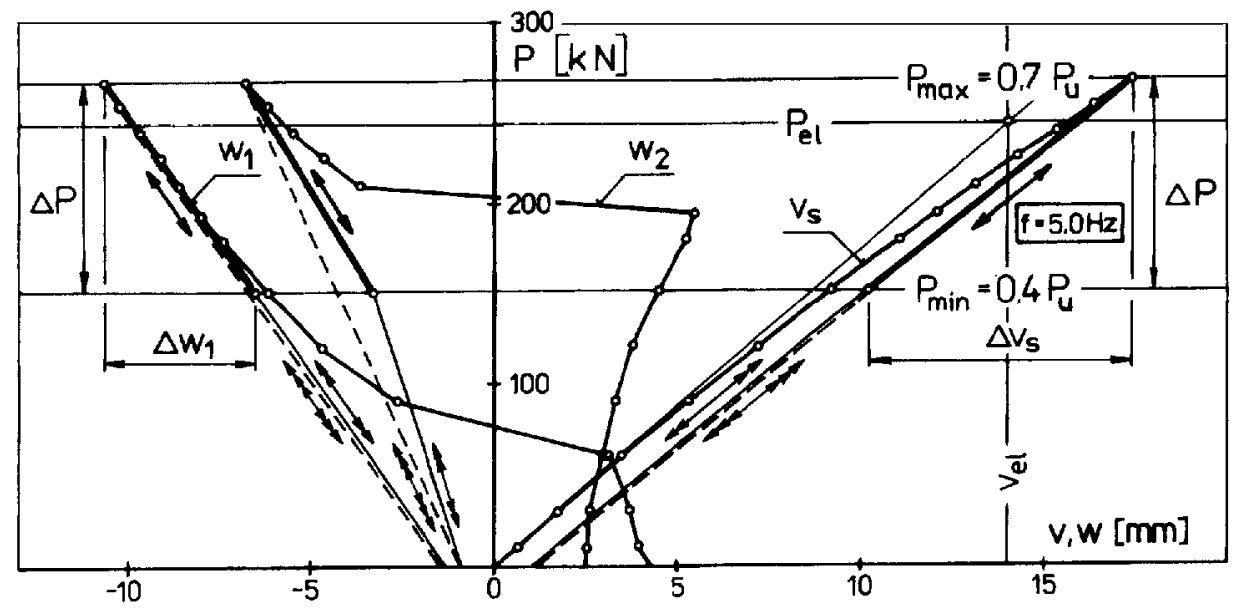

Fig. 2. Load - deflection relationships of the thin web and girder. Jumps over of the web in the most loaded fields.

Fig. 2 expresses the load-deflection relationships of the chosen girder $w_{s}$ in the middle cross-section and its web $w_{1}$ and $w_{2}$ in the central points of the two most loaded fields. The ultimate load of the girder with account of the web buckling and the elasto-plastic postcritical behaviour of the web is $P_{u}=382.2 \mathrm{kN}$. During the first loading the sudden jump over appeared in two most loaded web fields - in the web field $\mathrm{S}_{2-1}$ after $P=60 \mathrm{kN}$ and in the web field $\mathrm{S}_{2-2}$ after $P=195 \mathrm{kN}$. However, during the following repeating loading between $P=0$ and $P=P_{\max }$ (quasi-static loading) or between $P=P_{\min }$ and $P=P_{\max }$ (dynamic fatigue loading) any next jump over of the web did not appeared. Under repeating loading relatively quick stabilisation of deformations and deflections was set in and the web buckled or vibrated in the service shape.

\subsection{Formation and successive increase of the fatigue cracks}

The results of realised experimental investigation also proved that the lateral web vibration of plate girders can also cause the formation and successively increase of the fatigue cracks which are situated near the welded connections of the web with flanges and stiffeners. Therefore, the fatigue strength and life-time of plate girders with thin web depend besides the usual loading, material and construction influences also on the lateral web vibration. Fatigue cracks of the chosen tested girder are presented in Fig. 3.

This girder is especially interesting with fatigue cracks along compressed flange in all internal web fields. The first cracks 1 and 2 had appeared after 300000 and 400000 cycles, respectively. Later cracks were successively increasing, but only the initiation of the crack 5 along stiffener was decisive for the failure of the girder. The crack had spread very 
quickly to the tension flange in the form of crack 6 and the total failure of girder was completed after 1342000 cycles.
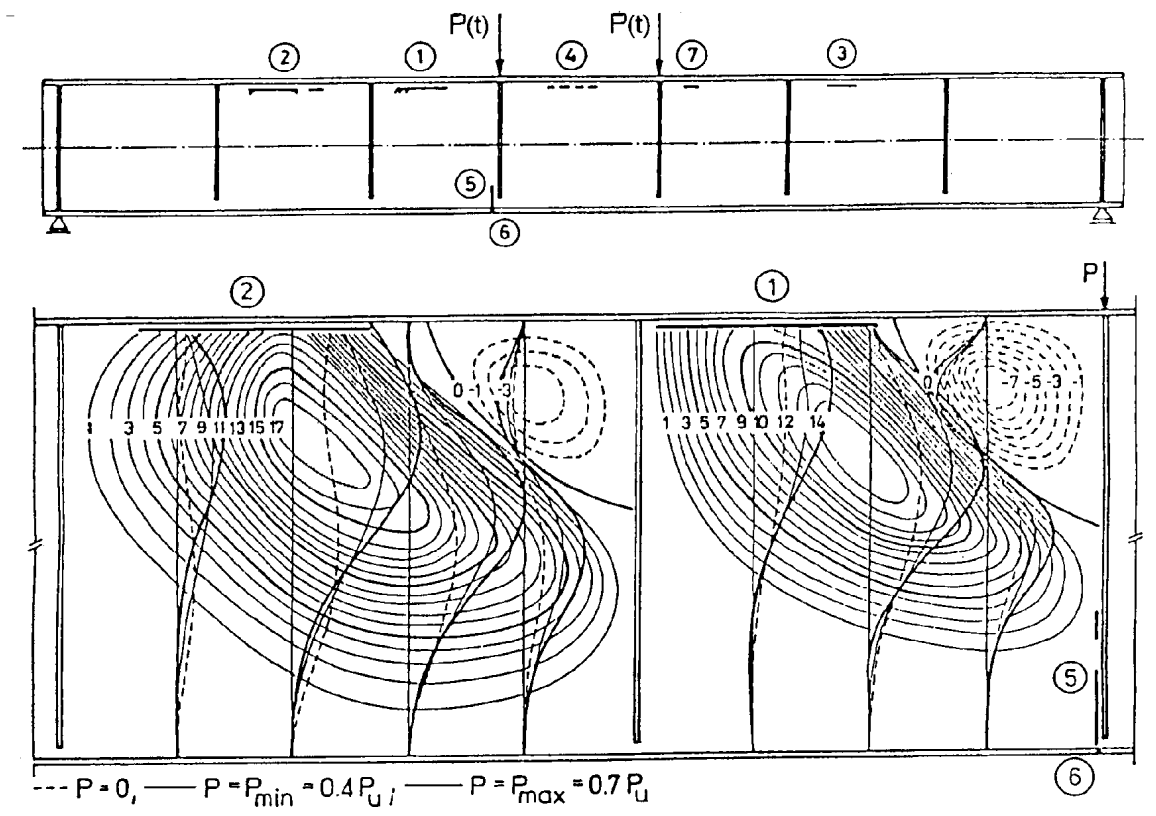

Fig. 3. Fatigue cracks in the thin web along welded connections with compression flange and transverse stiffener; crack in tension flange. Final topography of the most failed fields.

Three types of the fatigue cracks appeared in the tested girders. The crack of the type 1 $(1,2,3,4,7)$ is in the web under the compression flange, it is spreading along the fillet welding. It can pass also into the web depending from the membrane stresses. The crack of the type 2 (5) is in the tension web part, it is passing along the stiffener to tension flange. The crack of the type 3 (6) is in the tension flange, it appears after developing of the crack of type 2. The intensity of the crack's propagation for different crack types is the important factor of the complex life-time evaluation of plate girders. Due to our results there is difference in the crack's propagation velocity. The slowest cracks were those of the type 1, the fastest were cracks of the type 3 and cracks that are the results of production defects.

\subsection{Limit criterion for the design of plate girders subjected to fatigue loading}

The realised investigation was especially directed on the fatigue cracks of type 1 and 2 . The fatigue crack of type 1 is illustrated in Fig. 4. These cracks depend first of all on the secondary transverse bending stresses along flanges and on their changes during loading process. These bending stresses of the web can be reduced above all by their slenderness $\beta$. Therefore, the web slenderness should be adequately limited.

According to the results of realised investigation and taking into account the results of previous researches [7-10] the maximum slenderness of the web for the plate girders subjected mostly to bending is:

$$
(280 / \sqrt[7]{N}) \sqrt{235 / f_{y f}},
$$

$N$ is needed, or required number of cycles and $f_{y f}$ is yield stress of flanges. 


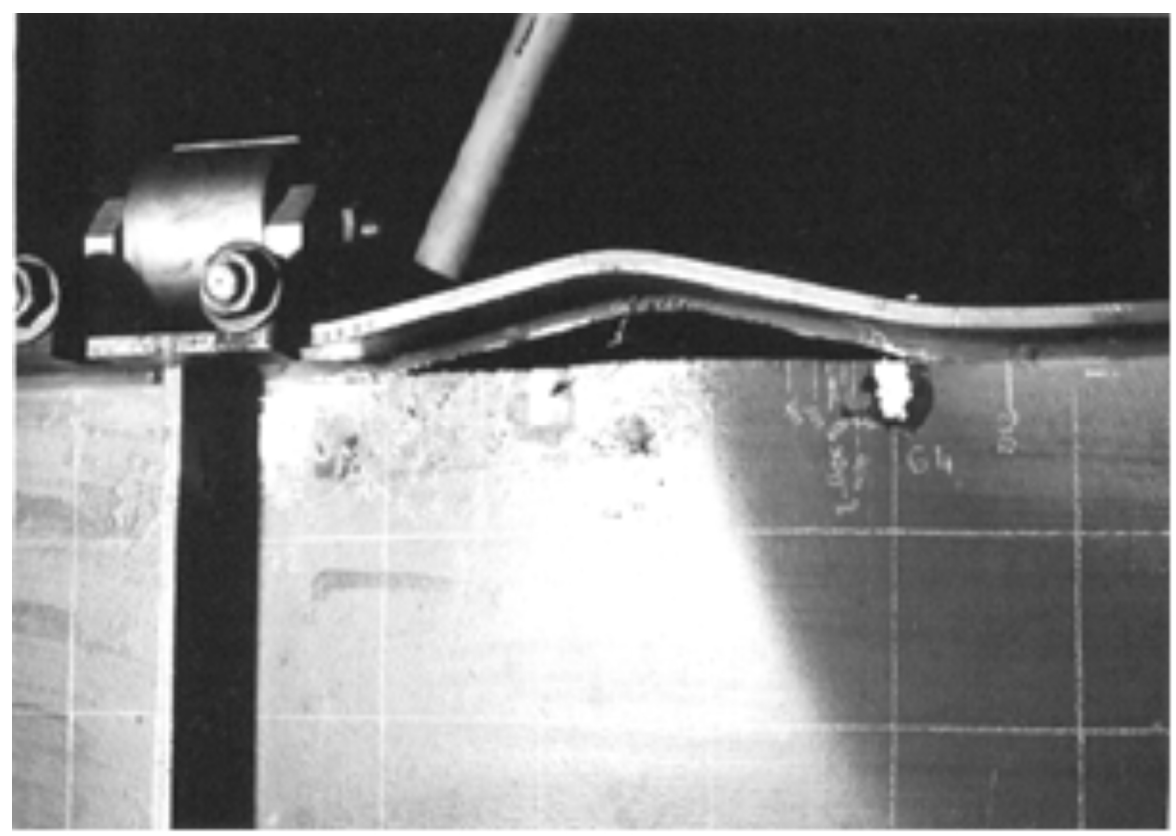

Fig. 4. Fatigue crack of type 1, local stability failure of the compression flange.

\section{Conclusions}

The realised investigations have proved that the service shapes of buckling and vibration are decisive for the analysis of behaviour of thin-walled plate girders. The lateral web vibration of plate girders can cause formation and successive increasing of failure cracks which are situated near the welded connections of the web with flanges and stiffeners. Therefore, the fatigue strength of plate girders with thin web depends besides the usual loading, material and construction influences also on the lateral web vibration. Deformation and increasing of fatigue cracks in thin webs of plate girders depend especially on the bending stresses along flanges and stiffeners and on their changes during loading process. The bending stresses of the web can be reduced above all by their slenderness $\beta$. Therefore, the web slenderness should be adequately limited according to presented proposal.

\section{References}

1. L.S. Beedle, et al., Stability of Metal Structures - A World View, Headquarters, Bethlehem (1991)

2. T.V. Galambos, et al., Guide of Stability Design Criteria for Metal Structures Structural Stability Research Council, J. W., New York (1998)

3. P. Juhás, et al., Design of Steel Structures - Commentary to STN 73 1401, SUTN, Bratislava (2001)

4. Y. Maeda, I. Okura, I., Influence of Initial Deflection of Plate Girder Webs on Fatigue Crack Initiation, Eng. Struct., 5, 1, 58-66 (1983)

5. P. Juhás, Thin-Walled Combined Plate Girders, Stav. Čas., 35, 12 (1987), p. 871-907

6. P. Juhás, Fatigue Failure of Thin-Walled Combined Plate Girders, Stav. Čas., 38, 11, 819-847 (1990)

7. I. Okura, B.I. Yen, J.W. Fischer, Fatigue Strength of Thin-Walled Plate Girders, Struct. Engin. Inter., 1, 1, 39-44 (1993) 
8. P. Juhás, Fatigue Failure Mechanism of Steel Elements, Extending of Lifespan of Structures, IABSE Symposium, San Francisco, 1085-1090 (1995)

9. P. Juhás, E. Juhásová, Local Stability and Load-Carrying Capacity of Plate Girders Subjected to Repeated Loading, Proc. of Struct. Stability Research Council - Annual Technical Session and Meeting, Memphis, 257-266 (1998) 